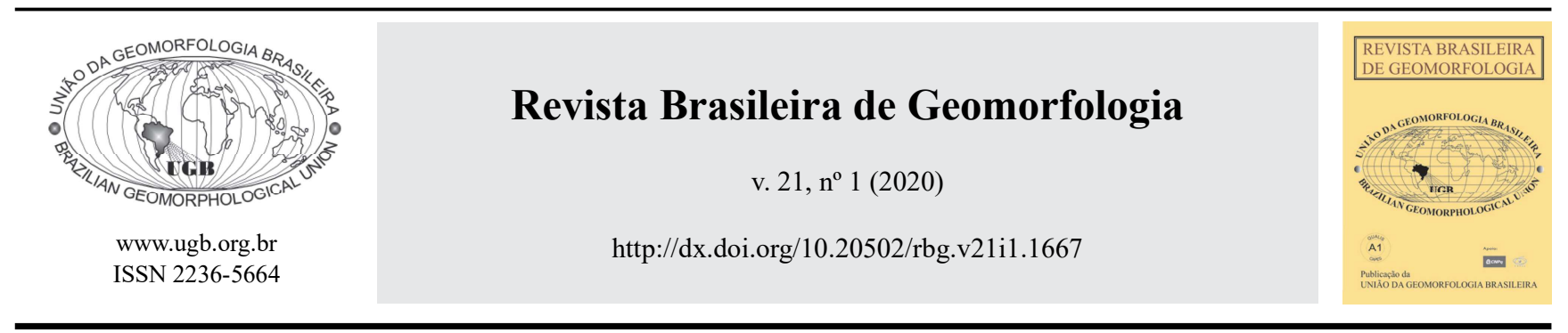

\title{
DISTRIBUIÇÃO DA FORMAÇÃO BARREIRAS NA REGIÃO SUL DO ESPÍRITO SANTO E SUA RELAÇÃO COM A DEFORMAÇÃO NEOTECTÔNICA
}

\section{DISTRIBUTION OF BARREIRAS FORMATION IN SOUTHERN OF ESPÍRITO SANTO STATE (SOUTHEASTERN BRAZIL) AND ITS RELATIONSHIP TO NEOTECTONIC DEFORMATION}

\author{
Daniel Carvalho West \\ Departamento de Geologia, Universidade Federal do Rio de Janeiro \\ Av. Athos da Silveira Ramos, 274, Rio de Janeiro, Rio de Janeiro. CEP: 21941-916, Brasil \\ ORCID: 0000-0002-4380-9817 \\ E-mail: danielwest011@hotmail.com
}

Claudio Limeira Mello

Departamento de Geologia, Universidade Federal do Rio de Janeiro Av. Athos da Silveira Ramos, 274, Rio de Janeiro, Rio de Janeiro. CEP: 21941-916, Brasil

ORCID: 0000-0002-0456-3367

E-mail: limeira@geologia.ufrj.br

\section{Informações sobre o Artigo}

Recebido (Received):

07/05/2019

Aceito (Accepted):

17/10/2019

Palavras-chave:

Formação Barreiras; Tabuleiros Costeiros; Tectônica Cenozoica.

\section{Keywords:}

Barreiras Formation; Coastal Tablelands; Cenozoic Tectonics.

\section{Resumo:}

A Formação Barreiras é uma unidade litoestratigráfica terrígena, de idade miocênica, com distribuição ao longo da costa brasileira, entre os estados do Amapá e do Rio de Janeiro, associada a uma típica morfologia de tabuleiros. Devido a sua ampla distribuição e idade, a unidade é tratada como um marco estratigráfico e geomorfológico para estudos neotectônicos. O presente estudo tem por objetivo analisar a distribuição dos depósitos da Formação Barreiras na região sul do Espírito Santo, entre o rio Itabapoana (divisa com o Rio de Janeiro) e a cidade de Guarapari, discutindo a sua relação com a deformação neotectônica. Foi realizado o mapeamento das ocorrências da Formação Barreiras em uma escala de 1:25.000 através da delimitação dos terrenos com a morfologia de tabuleiros, em contraste com os padrões morfológicos das unidades adjacentes (embasamento cristalino e sedimentos quaternários). Essa etapa foi efetuada sobre hillshades derivados de modelo digital de elevação de alta resolução, obtidos a partir de pares de ortofotos com pixel de 1 metro. Análises estruturais envolveram a extração e a quantificação de lineamentos, assim como a medição de pares falha/estria afetando os depósitos da Formação Barreiras e coberturas mais recentes, com a interpretação dos campos de paleotensões associados. Três áreas principais de ocorrência dos depósitos da Formação Barreiras foram individualizadas, a mais extensa situada entre os rios Itabapoana e Itapemirim. Essas áreas apresentam limites NE-SW, relacionados a alinhamentos de altos topográficos do embasamento, e NW-SE a NNW-SSE, associados às drenagens principais e áreas de exposição do embasamento em terrenos colinosos. Em direção ao interior, os 
depósitos da Formação Barreiras encontram-se mais dissecados e afloram com menor espessura, até formarem apenas uma delgada capa sobre o embasamento. A morfologia de tabuleiros apresenta, em geral, um caimento suave para o litoral, apresentando desníveis topográficos com orientações NE-SW que definem diferentes blocos, porém alguns com caimento para o interior. Destaca-se ainda a presença de altos de embasamento de direção NE-SW limitando setores onde os tabuleiros estão topograficamente rebaixados. Tais aspectos sugerem um controle por falhas normais, formando grábens e horstes. Os tabuleiros também estão compartimentados em blocos com orientações NW-SE a NNW-SSE, com basculamento principalmente para NE, sugerindo uma estruturação em hemigrábens. Os dados estruturais analisados sustentam a interpretação de controles por mecanismos neotectônicos na compartimentação dos tabuleiros, sendo reconhecidas duas fases deformacionais. A primeira fase é caracterizada por falhas normais NW-SE e falhas transcorrentes NNW-SSE, NNE-SSW e ENE-WSW, atribuídas a um evento de transcorrência dextral E-W, ao qual estariam associadas as feições morfológicas de orientação NW-SE e NNW-SSE. Uma segunda fase, mais recente, é caracterizada por falhas normais NE-SW, atribuídas a um evento de distensão NW-SE, ao qual são associadas as feições morfológicas NE-SW.

\begin{abstract}
:
The Barreiras Formation is a Miocene terrigenous litostratigraphic unit, with a large occurrence along the Brazilian coast between Rio de Janeiro and Amapá states, whose distribution is associated with morphologies of coastal tablelands and cliffs. Because of its wide distribution and Miocene age, this unit is assigned as a stratigraphical and geomorphological mark to neotectonic studies. The present study aims to analyze the distribution of Barreiras Formation deposits in the southern portion of the Espírito Santo State (Southeastern Brazil), between Itabapoana river (at the boundary with the Rio de Janeiro State) and the city of Guarapari, in order to discuss probable relationships to neotectonic deformation. A mapping of occurrences of the Barreiras Formation on a 1:25,000 scale was accomplished by delimiting the terrains with the typical morphology of tablelands associated with this unit, in contrast to the morphological patterns of the adjacent geological units (crystalline basement and Quaternary sediments). This map was delimited on hillshades derived from a high resolution digital elevation model, obtained from ortophotos pairs with 1 meter pixel. Structural analyzes involved extraction and quantification of lineaments, and measurements of fault/striae pairs affecting the Barreiras Formation deposits and younger deposits, followed by paleostress interpretation. Three main areas of occurrence of the Barreiras Formation deposits were individualized, being the most extensive of them located between Itabapoana and Itapemirim rivers. These areas have NE-SW limits, related to high topographic alignments of basement rocks, and NW-SE to NNW-SSE limits, associated with the main drainages and basement exposures in hilly areas. Towards the interior, the deposits of the Barreiras Formation are more dissected and appear with minor thickness until they form only a thin layer capping the crystalline basement. The morphology of tablelands commonly presents a smooth slope to the coast, showing NE-SW topographic steps which define different blocks, some of them dipping to the interior. It stands out the presence of NE-SW basement highs which limit sectors where the tablelands are topographically lowered. These aspects suggest a control by normal faults, forming grabens and horsts. The tablelands are also compartmentalized in NW-SE to NNW-SSE blocks, mainly dipping to NE, suggesting a hemigraben conformation. The structural data support an interpretation of neotectonic controls on the compartmentalization of the tablelands, being recognized two deformational phases. The first phase is characterized by NW-SE normal faults and NNW-SSE, NNE-SSW and ENE-WSW transcurrent faults attributed to an E-W dextral transcurrent event, associated with NW-SE and NNW-SSE morphological features. A younger phase is characterized by NE-SW normal faults, attributed to a NW-SE distension event, associated with NE-SW morphological features.
\end{abstract}

\section{Introdução}

A Formação Barreiras é uma unidade litoestratigráfica de idade miocênica (Arai, 2006; Lima, 2008) com ampla ocorrência na costa brasileira, desde o
Amapá até o Rio de Janeiro, representando um importante marco estratigráfico do Cenozoico do Brasil. Ao longo de toda a sua área de abrangência, marcada por uma morfologia de tabuleiros costeiros, a unidade vem sendo estudada por diferentes pesquisadores, que 
discutem, entre outras, as seguintes questões principais: distribuição e limites com as unidades geológicas adjacentes; ambientes de sedimentação; idade; relação com a tectônica cenozoica (Suguio \& Nogueira, 1999). Quanto à relação com a tectônica cenozoica, tendo em vista a idade miocênica atualmente aceita, a Formação Barreiras assume grande importância como balizador estratigráfico nos estudos da deformação neotectônica na margem continental brasileira (Saadi, 1999; Furrier et al., 2006; Nogueira et al., 2006; Bricalli \& Mello, 2013; Bezerra et al., 2014; Brêda et al., 2018).

Diversos estudos que vêm sendo realizados na área de ocorrência da Formação Barreiras no Sudeste do Brasil (litoral norte do Rio de Janeiro e litoral do Espírito Santo), na porção emersa das bacias de Campos e do Espírito Santo, destacam o controle neotectônico na distribuição descontínua dessa unidade (Ribeiro, 2010; Brêda, 2012; Chrismann, 2014; Rodrigues, 2015; West, 2017). Dentre os resultados obtidos nesses estudos, foi reconhecido por Ribeiro (2010), na região entre o rio Paraíba do Sul (RJ) e o rio Doce (ES), um padrão de compartimentação dos tabuleiros da Formação Barreiras em blocos rebaixados e soerguidos, formando grábens/ hemigrábens e horstes, controlados principalmente por estruturas de direção NW-SE. Esse modelo, também considerado para a distribuição da Formação Barreiras em áreas no Nordeste brasileiro (Nogueira et al., 2006), sugere que a ocorrência mais descontínua dos tabuleiros costeiros no litoral sul do estado do Espírito Santo, em contraste com a maior continuidade na região a norte de Vitória (ES) e no norte fluminense, indica se tratar de um setor mais soerguido ou deformado por mecanismos neotectônicos.

Nesse contexto, o presente estudo tem por objetivo investigar, em uma escala de detalhe (1:25.000), a distribuição da Formação Barreiras na região costeira do sul do Espírito Santo e sua relação com a deformação neotectônica, a partir da integração de análises geomorfológicas (identificação de padrões de relevo) e estruturais (análise de dados de lineamentos e de estruturas rúpteis).

\section{Contexto geológico-geomorfológico}

A área de estudo localiza-se entre o rio Itabapoana (que faz a divisa dos estados do Espírito Santo e Rio de Janeiro) e a cidade de Guarapari (ES) - Figura 1. Está incluída na área coberta pelas seguintes folhas topográficas 1:50.000 do Instituto Brasileiro de Geografia e Estatística (IBGE): Mimoso do Sul; Presidente Kennedy; Itapemirim; Cachoeiro do Itapemirim; Rio Novo do Sul; Piúma; Matilde; Alfredo Chaves.

Quanto à geologia regional, a área pode ser dividida em dois domínios principais: Terrenos do Embasamento Neoproterozoico-Eopaleozoico; e Terrenos Sedimentares Cenozoicos.

O domínio do embasamento é caracterizado por complexos gnáissicos e suítes intrusivas, predominando um trend estrutural de orientação NE-SW, relacionando-se à Faixa Móvel Ribeira, na porção central da Província Mantiqueira (Vieira \& Menezes, 2015). Esses terrenos apresentam aspectos de alta rugosidade, com morfologia serrana a colinosa, alta densidade de drenagens, com diminuição das cotas altimétricas em direção à região costeira, compondo os seguintes domínios geomorfológicos reconhecidos por Silva \& Machado (2014 - Figura 1): Montanhoso; Morros e Serras Baixas; Colinas Dissecadas e de Morros Baixos; e Colinas Amplas e Suaves.

Os terrenos sedimentares cenozoicos são representados pela Formação Barreiras (Mioceno) e por sedimentos quaternários diversos, no contexto da evolução da Bacia de Campos. A Formação Barreiras, na área, é caracterizada por depósitos sedimentares continentais, de origem fluvial e com a contribuição de leques aluviais (Morais, 2007). Essa unidade é associada à morfologia de Tabuleiros e Tabuleiros Dissecados (Silva \& Machado, 2014 - Figura 1), caracterizada por topos amplos e planos, ocupando áreas topograficamente mais baixas em relação aos terrenos do embasamento, com baixa a moderada densidade de drenagem e vales profundamente entalhados. Os sedimentos quaternários são relacionados aos domínios geomorfológicos de Planícies Marinhas ou Flúvio-marinhas e Planícies Fluviais ou Flúvio-lacustres (Silva \& Machado, 2014 - Figura 1).

\section{Métodos e técnicas}

O desenvolvimento do estudo envolveu duas etapas principais (mapeamento da Formação Barreiras e análise estrutural), cujas atividades e produtos estão sintetizados na Figura 2. 
West D. C. \& Mello C. L.

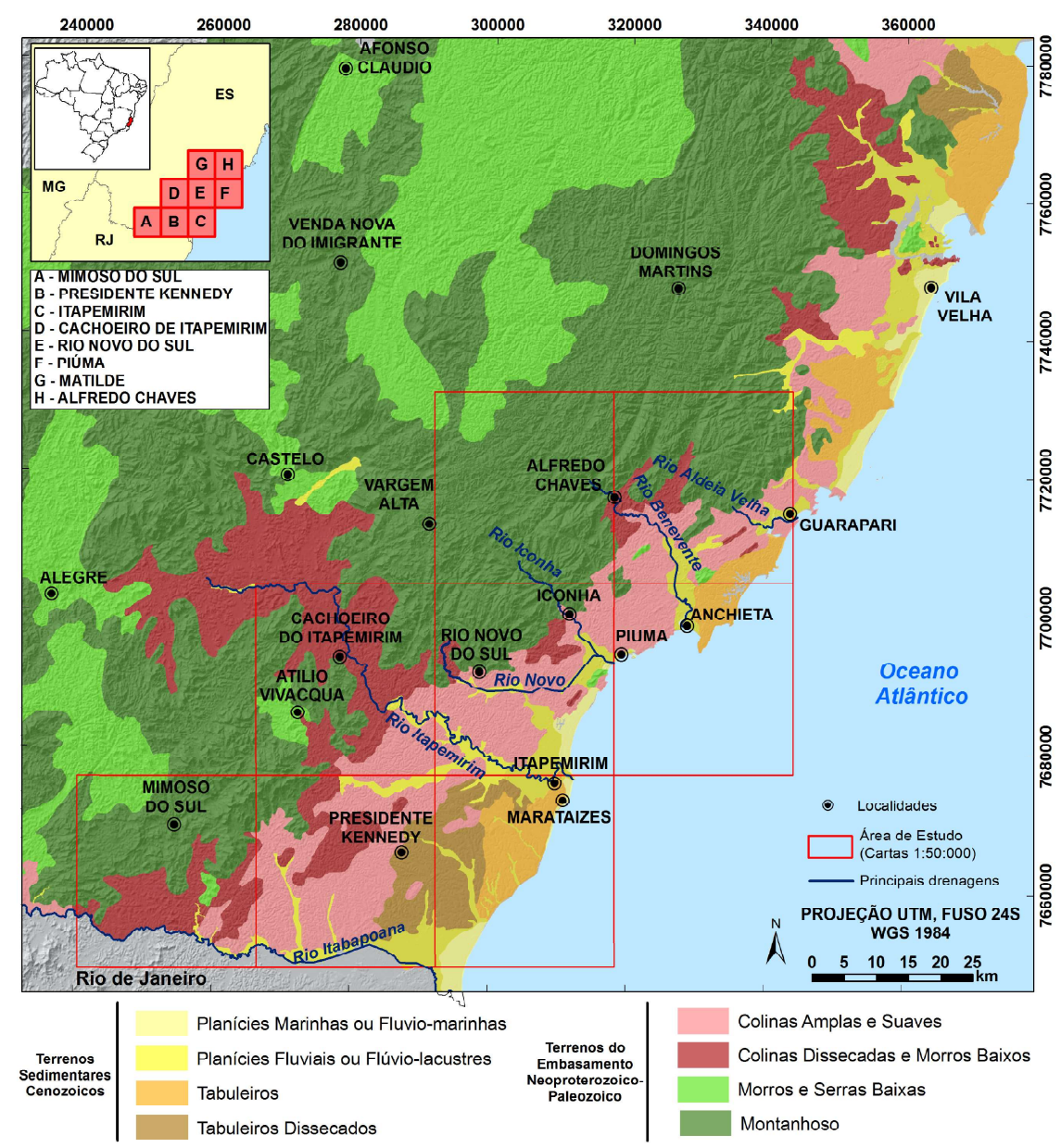

Figura 1 - Mapa de unidades geomorfológicas na região sul do Espírito Santo, com base em Silva \& Machado (2014), sobre o hillshade (azimute $315^{\circ}$ e altitude $45^{\circ}$ ) elaborado a partir do MDE do IEMA. Estão demarcadas as folhas topográficas (IBGE, 1:50.000) que cobrem a área de interesse.

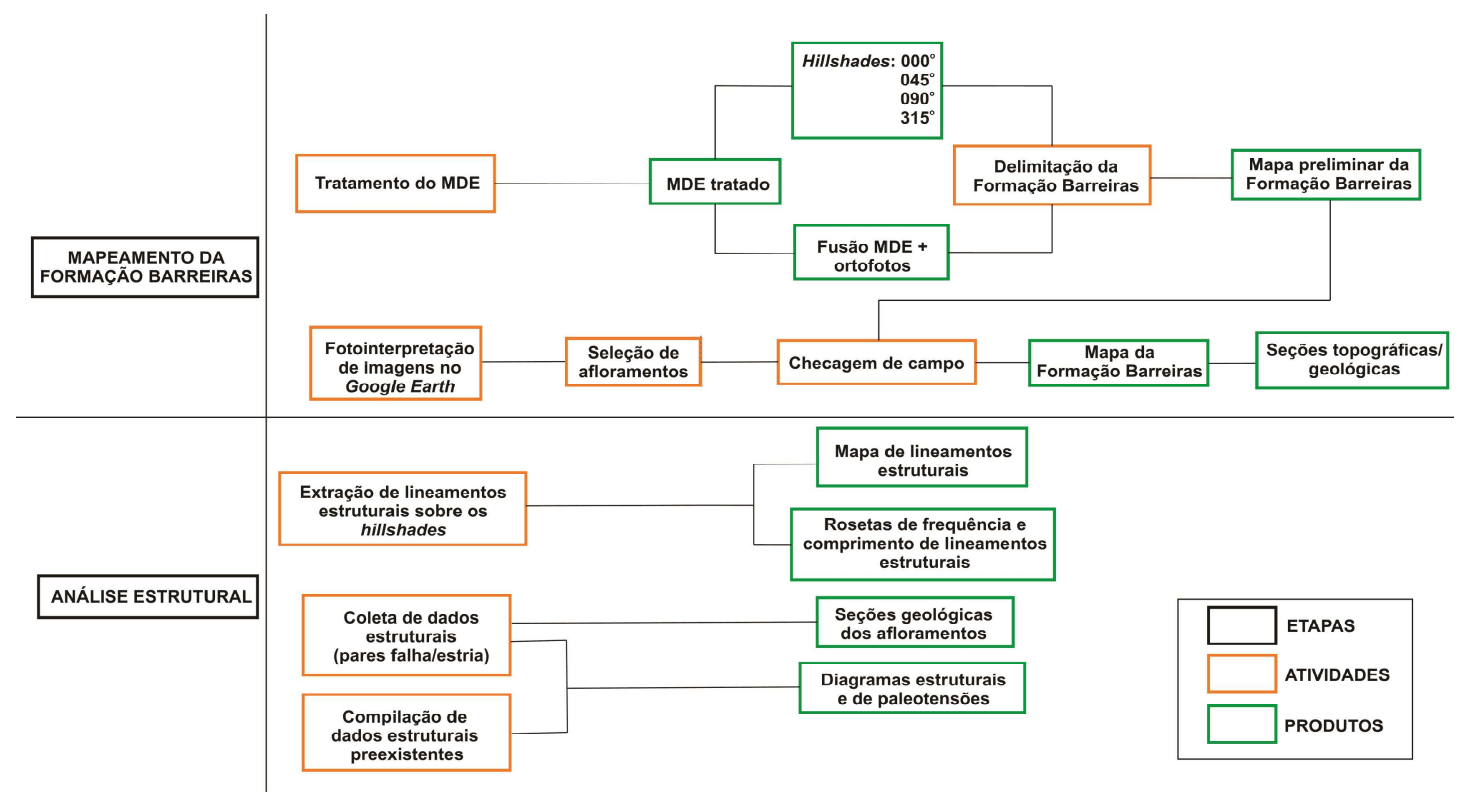

Figura 2 - Fluxograma das etapas metodológicas e atividades desenvolvidas no presente estudo, com a indicação dos principais produtos obtidos. Foi utilizado um modelo digital de elevação de alta resolução (pixel de 5 metros), gerado pelo IEMA (Instituto Estadual do Meio Ambiente do Espirito Santo) a partir de pares de ortofotos (pixel de 1 metro). 
Para a etapa de mapeamento da Formação Barreiras, foi utilizado como base cartográfica um modelo digital de elevação (MDE) de alta resolução (pixel de 5 metros) elaborado pelo Instituto Estadual de Meio Ambiente e Recursos Hídricos do Estado do Espírito Santo (IEMA-ES) e as ortofotos (pixel de 1 metro) que serviram de base para a sua elaboração. Esses materiais foram cedidos pelo Serviço Geológico do Brasil/ Companhia de Pesquisa de Recursos Minerais (CPRM).

$\mathrm{O}$ estudo foi iniciado pelo tratamento do MDE com uso do filtro Focal Statistics e da ferramenta Mask do Spatial Analyst Tools no software ESRI ArcMap 10.1 $1^{\circledR}$. Após três aplicações consecutivas do filtro, o MDE resultante mostrou-se mais coerente e com melhor definição visual, facilitando a identificação dos padrões de relevo em relação ao dado original.

A partir do MDE tratado, foram gerados quatro hillshades utilizando a ferramenta Hillshade do $3 D$ Analyst Tools no ESRI ArcMap 10.1 ${ }^{\circledR}$. Foram utilizados quatro azimutes de iluminação $\left(000^{\circ}, 045^{\circ}, 090^{\circ}, 315^{\circ}\right)$, um para cada hillshade, e valor de altitude de iluminação de $45^{\circ}$. Os diferentes azimutes foram adotados a fim de destacar toda a variedade de orientações de feições morfológicas presentes, como base importante para a etapa de análise estrutural. Os azimutes utilizados estão entre $270^{\circ}$ e $90^{\circ}$ para evitar o efeito de inversão de relevo comumente observado em hillshades elaborados com azimutes entre $91^{\circ}$ e $269^{\circ}$. Sobre os hillshades gerados, foi efetuada, no software ESRI ArcMap 10.1 ${ }^{\circledR}$, a intepretação dos padrões de relevo na área de interesse, através do reconhecimento visual dos elementos morfológicos que compõem cada domínio geológico principal (Formação Barreiras, Embasamento Cristalino e Sedimentos Quaternários), resultando em um mapa preliminar da Formação Barreiras em escala de detalhe (1:25.000).

O mapa preliminar passou por uma etapa de refinamento de seus limites através da interpretação de um produto gerado pela fusão do MDE tratado com as ortofotos. A fusão foi elaborada com uma sobreposição dos arquivos no software Global Mapper $18^{\circledR}$ e o uso da ferramenta Texture Map, adicionando uma iluminação artificial de altitude $75^{\circ}$ e azimute $025^{\circ}$, segundo metodologia utilizada por Shinzato et al. (2012). Essa técnica realça o contraste entre formas de relevo, como morros e a posição das drenagens, permitindo uma melhor delimitação dos elementos geomorfológicos.

Foram realizadas atividades de campo para a checa- gem do mapa preliminar, precedidas pela fotointerpretação de imagens de satélite disponíveis no Google Earth ${ }^{\circledR}$, com a identificação de pontos de interesse para investigação em campo. Buscou-se identificar locais com melhor exposição dos materiais geológicos, como cortes de rodovias, cavas e exposições naturais (por exemplo falésias e voçorocas), que permitissem a descrição litológica em campo. Ao final, foi elaborado o mapa de ocorrências da Formação Barreiras em escala de detalhe (1:25.000) na área investigada. Tendo como base esse mapa, foram construídas seções geológicas cuja topografia foi obtida do MDE tratado, com o uso do software Global Mapper $18^{\circledR}$.

A etapa de análise estrutural englobou a extração e classificação de lineamentos (segundo critérios propostos por Liu, 1987) e a coleta e compilação de dados de estruturas rúpteis (pares falha/estria) afetando os depósitos da Formação Barreiras, coberturas mais recentes e rochas do embasamento saprolitizadas.

Os lineamentos estruturais foram extraídos manualmente sobre os hillshades no software ESRI ArcMap $10.1^{\circledR}$. Foi realizada a medição automática dos azimutes e comprimentos dos lineamentos utilizando a extensão Easy Calculator 10 do ESRI ArcMap 10.1 ${ }^{\circledR}$, com a ferramenta Polyline Get Azimuth para calcular o azimute das feições e com a ferramenta Calculate Geometry para calcular o comprimento dos lineamentos. As feições delimitadas a partir da interpretação dos diversos hillshades foram integradas, resultando no mapa de lineamentos da área de estudo, sendo consideradas apenas as feições de comprimento maior ou igual a 1.000 metros, desconsiderando os lineamentos menores por sua pouca relevância na escala adotada.

Os lineamentos foram separados em seis intervalos: NNE-SSW (N-S a N30E); NE-SW (N31E a N60E); ENE-WSW (N61E a N90E); WNW-ESE (N90W a N61W); NW-SE (N60W a N31W); e NNW-SSE (N30W a N-S).

A análise de pares falha/estria incluiu informações coletadas em afloramentos selecionados durante as atividades de campo voltadas para o mapeamento dos depósitos da Formação Barreiras e também dados compilados do estudo realizado por Ribeiro (2010). Foram selecionados, nessa etapa, pontos com boa exposição da unidade e de coberturas mais recentes, que apresentassem feições estruturais rúpteis com deslocamento das camadas. Posteriormente, as falhas foram classificadas quanto a sua natureza (normal, transcorrente ou reversa) e unidade geológica afetada (Embasamento Cristalino, 
Formação Barreiras e/ou Sedimentos Quaternários). O sentido de deslocamento das falhas foi reconhecido com base em indicadores estratigráficos ou a partir de feições assimétricas presentes nos planos de falha, utilizando os padrões descritos por Angelier (1994). As estruturas medidas foram processadas em software específico (WinTensor $^{\circledR}$ - Delvaux \& Sperner, 2003), que se baseia na aplicação do método dos diedros retos (Angelier, 1994) para a obtenção de informações quanto às paleontensões, sendo gerados diagramas estruturais e de paleotensões.

\section{Resultados}

\subsection{Mapa de distribuição da Formação Barreiras}

A interpretação dos padrões de relevo a partir dos hillshades destacou os aspectos morfológicos característicos das unidades geológicas presentes na área de estudo (Figuras 3 a 6), que serviram de base para o reconhecimento preliminar da distribuição espacial da
Formação Barreiras (Figura 7):

- Formação Barreiras - associada a um relevo suavizado, com topos planos e amplos (morfologia de tabuleiros) e entalhamento profundo das drenagens (Figura 4), com baixa densidade de canais, ocupando geralmente cotas altimétricas entre 20 e 80 metros;

- Embasamento Cristalino - exibe dois padrões de relevo distintos (Figura 5), sendo um representativo do domínio montanhoso, com topos agudos e maiores altitudes, e outro associado ao embasamento mais intemperizado, com relevo suavizado, que se assemelha ao padrão da Formação Barreiras, podendo ser diferenciado pela maior dissecação fluvial e maior rugosidade; comumente a ocorrência do embasamento cristalino foi identificada em cotas altimétricas acima de 100 metros;

- Sedimentos Quaternários - diferenciados pelo padrão de áreas planas, contínuas, homogêneas, com menor contraste de relevo, ocupando os vales fluviais e as faixas costeiras - Figura 6.

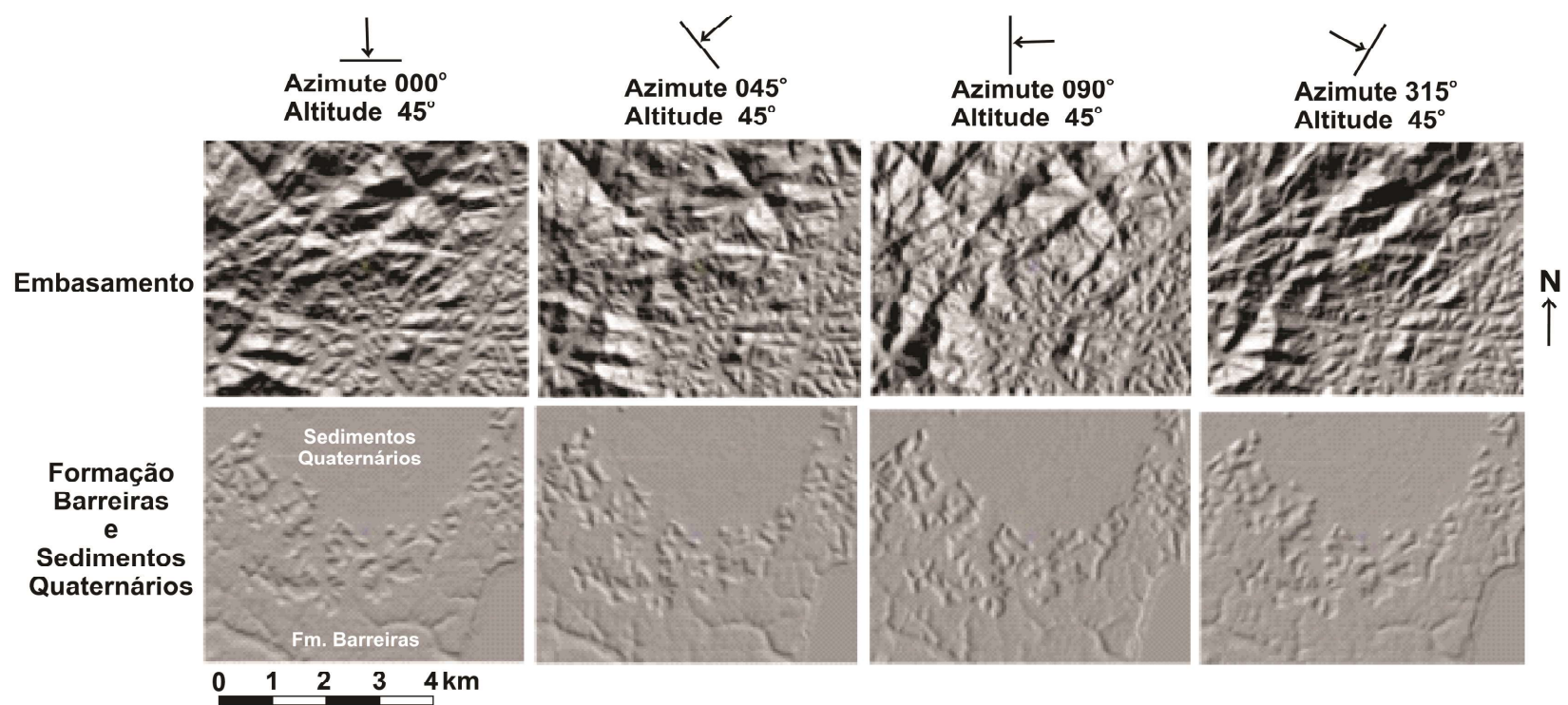

Figura 3 - Ilustração dos padrões de relevo associados às principais unidades geológicas na área de estudo, segundo os diferentes azimutes de iluminação aplicados.

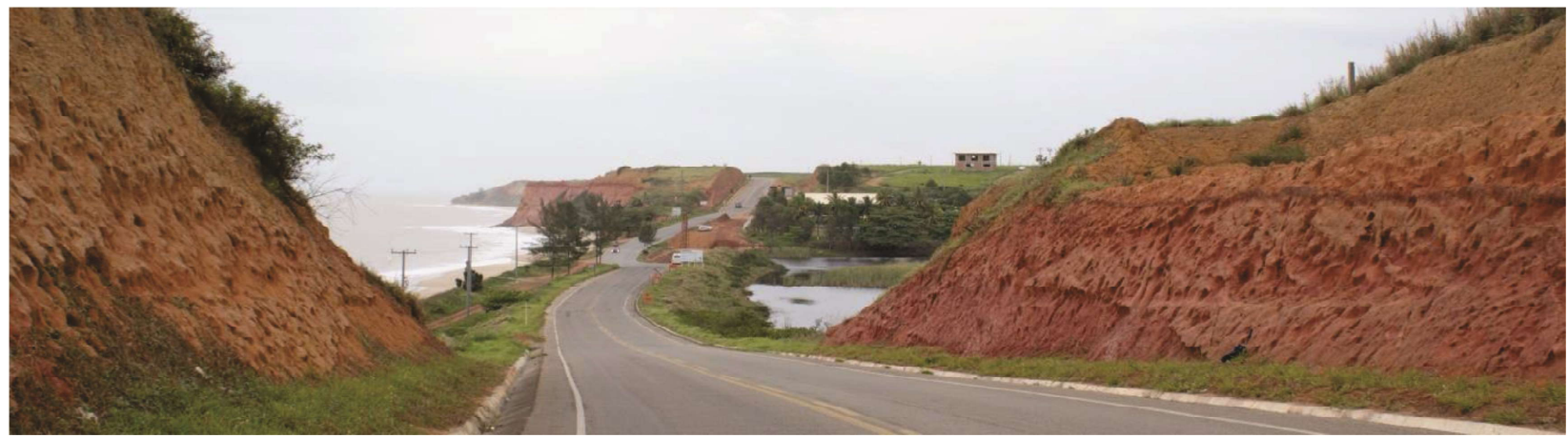

Figura 4 - Relevo de tabuleiros e falésias associado à Formação Barreiras, destacando-se também o padrão típico de drenagem profundamente entalhada. 


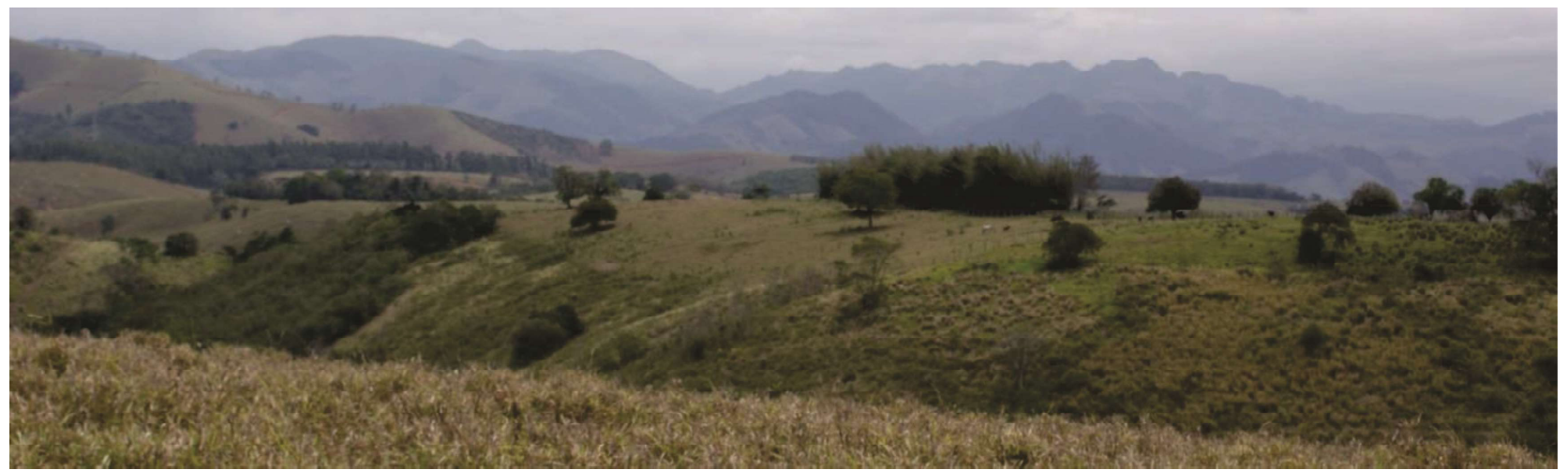

Figura 5 - Padrões de relevo associados aos terrenos do embasamento: colinas amplas e morros baixos e, ao fundo, domínio montanhoso.

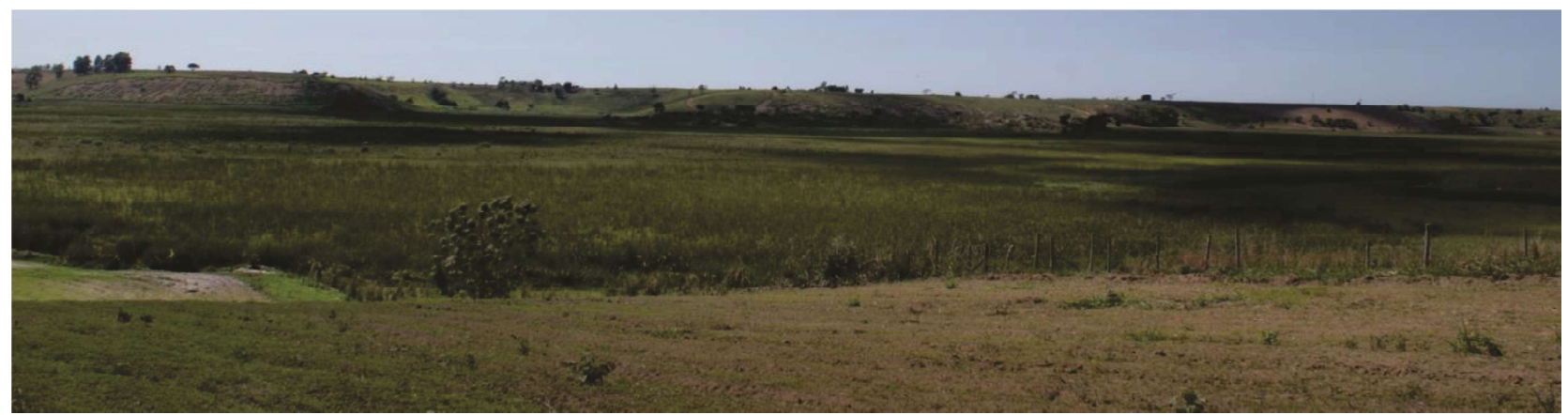

Figura 6 - Relevo típico dos terrenos quaternários na área de estudo. Planície fluvial do Brejo do Criador, drenagem encaixada nos tabuleiros da Formação Barreiras na região ao sul de Marataizes (ES).

Para a verificação em campo do mapa preliminar de distribuição da Formação Barreiras, foram visitados 188 pontos ao longo da área de estudo (Figura 7), sendo 87 pontos atribuídos ao embasamento, 24 ao embasamento coberto pela Formação Barreiras, e 77 à Formação Barreiras, incluindo pontos descritos em trabalhos anteriores (Morais, 2007; Alves, 2016), que foram revisitados.

O mapa resultante da integração da análise de padrões de relevo com os dados obtidos durante as etapas de campo corresponde ao mapa final de distribuição da Formação Barreiras na área de estudo (Figura 8).

A maior distribuição da Formação Barreiras na área de estudo está na região entre os rios Itabapoana e Itapemirim. Nessa porção, os depósitos da Formação Barreiras ocorrem de forma contínua, entalhados por drenagens de direção principal NW-SE. Destaca-se a ocorrência de "ilhas" de embasamento alinhadas com orientação NE-SW, que separam setores com diferentes graus de dissecação dos depósitos da Formação Barreiras. Quanto mais em direção ao interior (para oeste/noroeste), os depósitos da unidade encontram-se mais dissecados e afloram com menor espessura, até formarem apenas uma delgada capa de sedimentos sobre o embasamento (Figura 9). Nessa região de transição geomorfológica dos domínios de "Tabuleiros Dissecados" para o domínio de "Colinas Amplas e Suaves" (Silva \& Machado, 2014), o embasamento apresenta formas de topo aplainado em contraste com a forma convexa mais comum. Para a definição dos limites da Formação Barreiras nessa situação, foi necessário analisar cuidadosamente os valores altimétricos (entre 20 e 80 metros) e os padrões visuais presentes nos hillshades.

Em direção ao litoral, os tabuleiros menos dissecados estão associados a afloramentos contínuos dos depósitos da Formação Barreiras (Figura 10).

Entre os rios Itapemirim e Iconha, são raros os afloramentos da Formação Barreiras, sendo essa unidade mapeável apenas como manchas isoladas restritas à região de Itaoca e Itaipava, ao sul de Piúma. A área de ocorrência dessas manchas isoladas é limitada a oeste por uma forte orientação NE-SW. 
West D. C. \& Mello C. L.

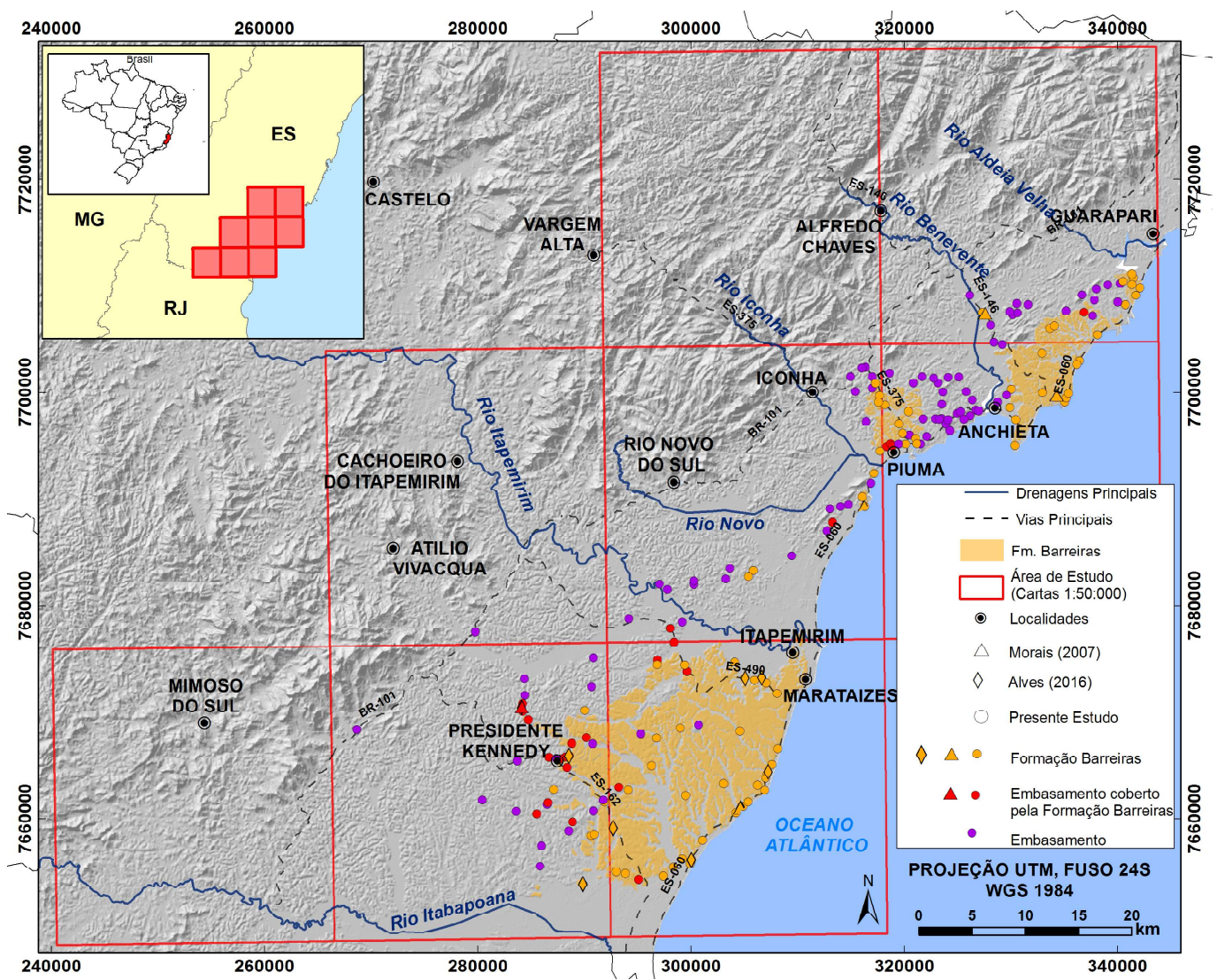

Figura 7-Mapa de pontos descritos nas atividades de campo, tendo como base o mapa preliminar de distribuição da Formação Barreiras (sobre o hillshade de azimute $315^{\circ}$ e altitude $45^{\circ}$, elaborado a partir do MDE do IEMA), incluindo pontos descritos em trabalhos anteriores (Morais, 2007; Alves, 2016) revisitados.

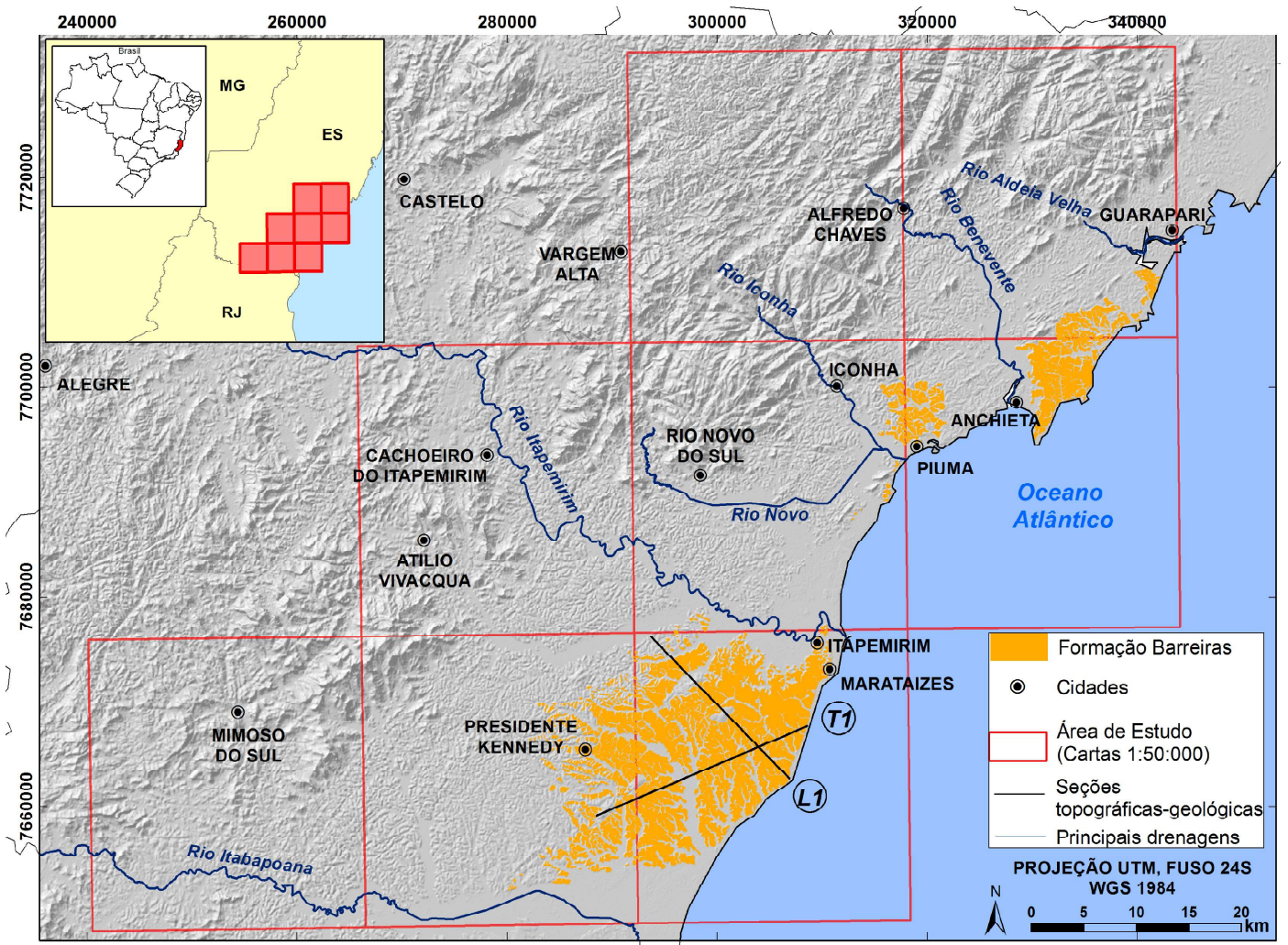

Figura 8-Mapa de distribuição da Formação Barreiras para a área de estudo sobre o hillshade de azimute $315^{\circ}$ e altitude $45^{\circ}$, elaborado a partir do MDE do IEMA. Estão indicadas as posições das seções topográficas/geológicas apresentadas nas Figuras 11 e 12. 


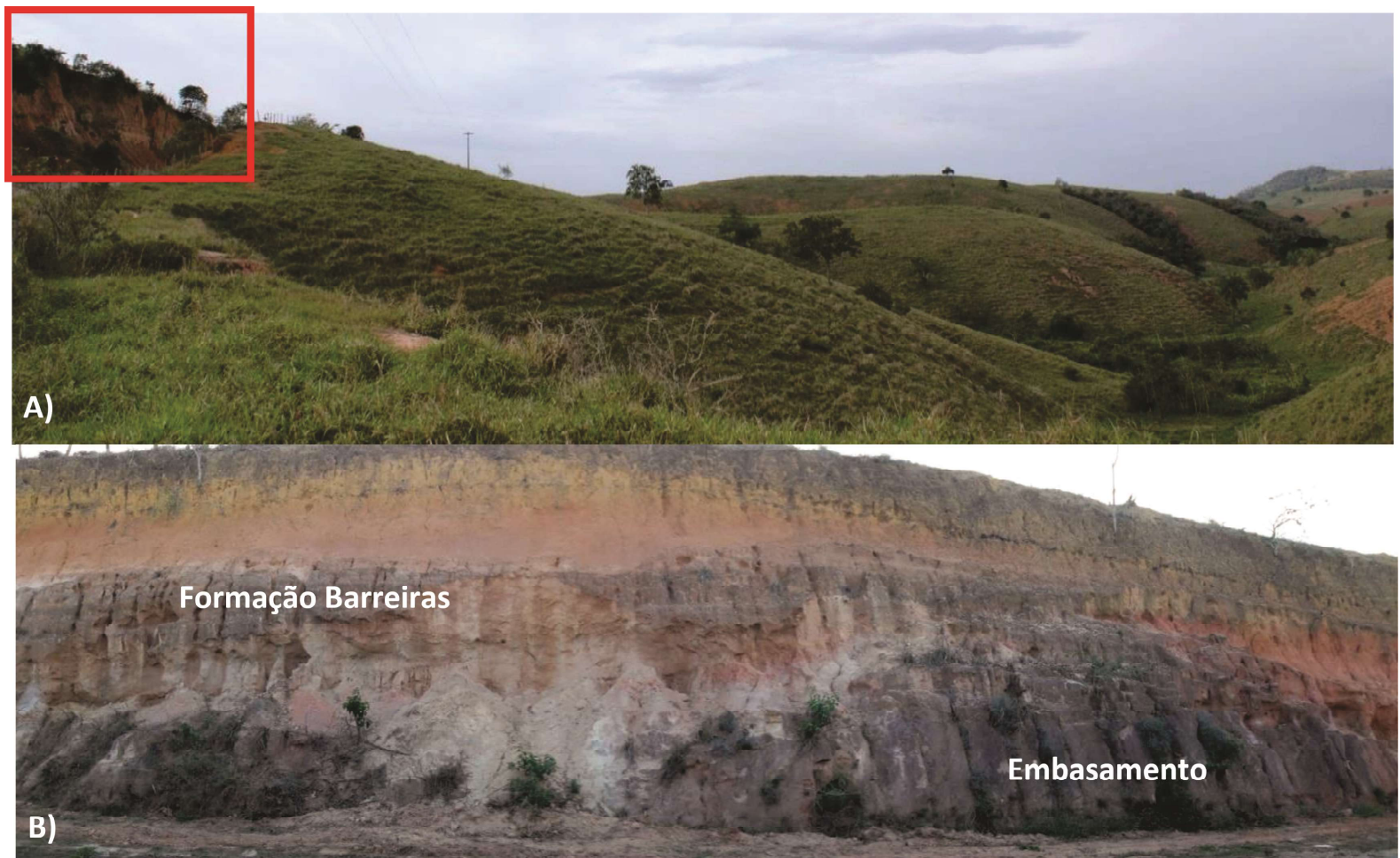

Figura 9 - A) Região de transição do domínio de Colinas Amplas e Suaves do embasamento para o domínio dos Tabuleiros Dissecados da Formação Barreiras, onde afloram rochas do embasamento com cobertura da Formação Barreiras, como visto no afloramento em (B). A posição do afloramento no relevo está assinalada pelo retângulo vermelho em (A). O domínio em questão apresenta colinas de topo aplainado em contraste com a forma convexa esperada para as colinas do embasamento. A forma plana do topo das colinas se assemelha ao padrão de tabuleiros típico da Formação Barreiras, reforçado pelas cotas altimétricas aproximadas.

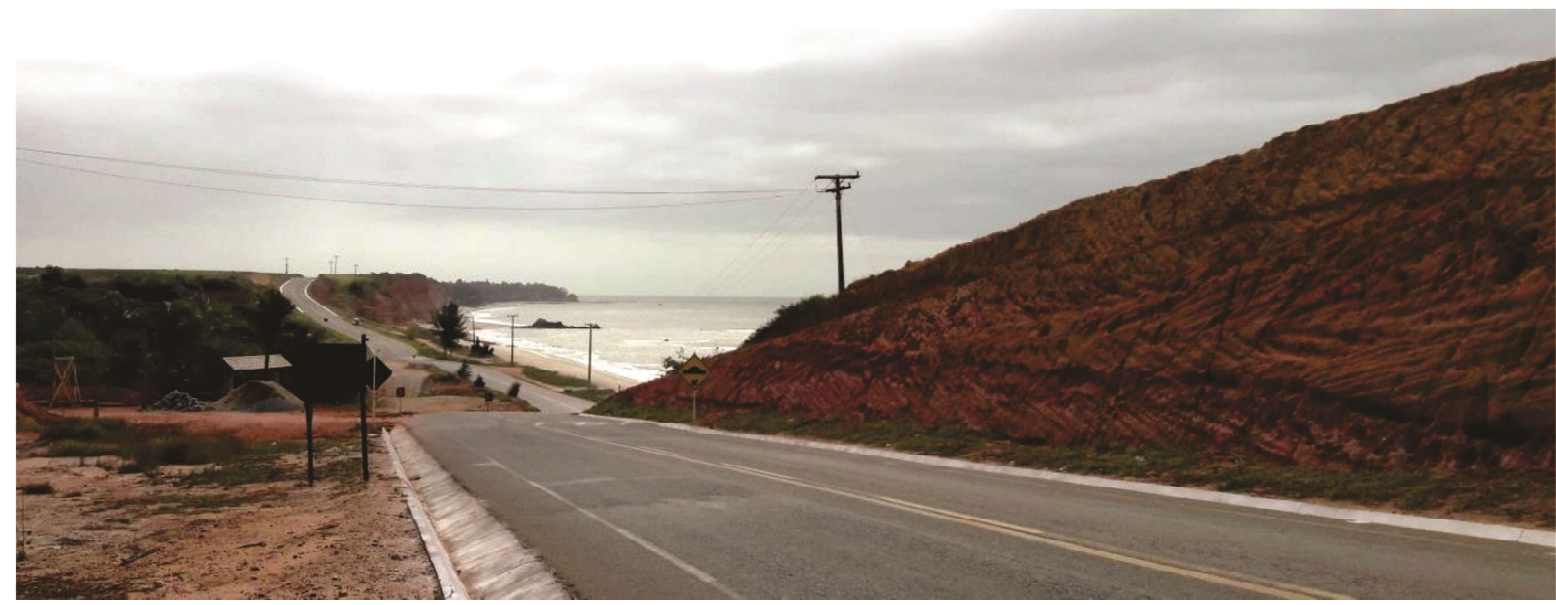

Figura 10 - Extensos afloramentos da Formação Barreiras em falésias no litoral sul do Espírito Santo. Notar também o padrão de relevo típico dos tabuleiros costeiros.

Na região entre os rios Iconha e Benevente (entre Piúma e Anchieta), a distribuição da Formação Barreiras é restrita a uma área com limites NW-SE bem evidenciados, também reconhecidos na área de ocorrência mais ao norte, entre os rios Benevente e Aldeia Velha (entre Anchieta e Guarapari). Nessa última área, os depósitos da Formação Barreiras estão novamente limitados a noroeste por um alto topográfico do embasamento com direção NE-SW, destacando-se uma clara segmentação, na altura de Meaípe, sob orientação NW-SE.

O padrão geral de distribuição dos depósitos da Formação Barreiras pode ser visualizado nas seções 
topográficas/geológicas elaboradas no principal setor de ocorrência da unidade (Figuras 11 e 12).

A seção longitudinal (Figura 11) mostra um padrão de caimento suave da superfície dos tabuleiros no sentido do litoral, com a redução da espessura da Formação Barreiras para o interior, até formar uma capa pouco espessa sobre as rochas do embasamento. As espessuras da Formação Barreiras foram em grande parte inferidas com base nas observações de campo, sendo reconhecidas áreas dos tabuleiros com afloramento de rochas do embasamento nas porções de média a baixa encosta. Ressalta-se a presença de altos de embasamento de orientação NE-SW limitando áreas topograficamente rebaixadas onde a Formação Barreiras está depositada, sendo sugestivo de um padrão controlado por falhas, formando grábens, enquanto os altos do embasamento representariam horstes. $\mathrm{O}$ aspecto de "embaciamento" é nítido em uma área de ocorrência da Formação Barreiras limitada por dois expressivos altos do embasamento. São também identificados desníveis topográficos relevantes nos tabuleiros, formando um padrão que se assemelha a uma compartimentação em blocos sob a influência de falhas normais sintéticas e antitéticas. Alguns desses blocos apresentam, inclusive, caimentos para o interior, contrários ao padrão geral.

A seção transversal (Figura 12) mostra uma compartimentação dos tabuleiros da Formação Barreiras em blocos topográficos controlados por estruturas de direção NW-SE a N-S. Esses blocos aparentam estar basculados principalmente para NE, sugerindo uma estruturação em hemigrábens. O modelo de estruturação em hemigrábens é reforçado pela assimetria topográfica em relação às bacias dos principais cursos de drenagem na área, como, por exemplo, o Brejo do Criador. Pode ser observado na seção transversal o caimento mais suave dos blocos dos tabuleiros na margem oeste do Brejo do Criador em relação ao desnível mais abrupto na sua margem leste.

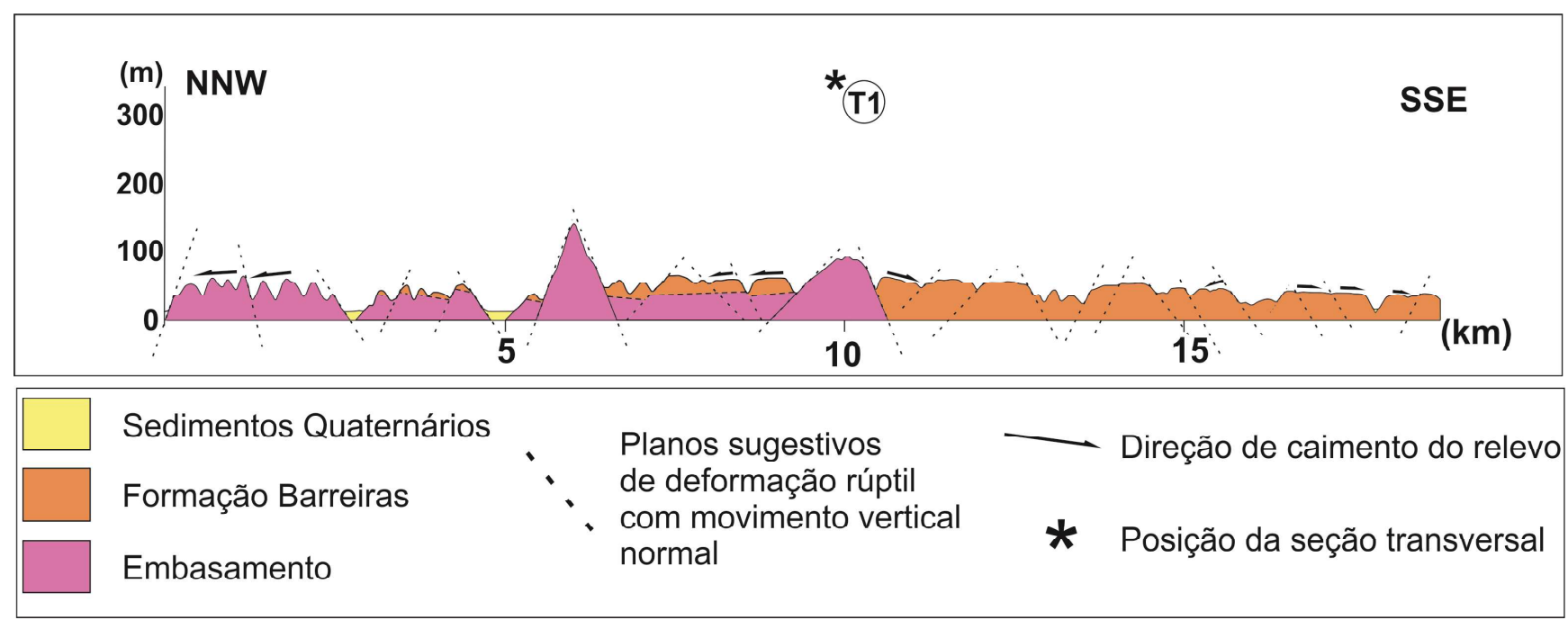

Figura 11 - Seção topográfica longitudinal (L1), com exagero vertical de aproximadamente 10 vezes. Ver localização na Figura 8.

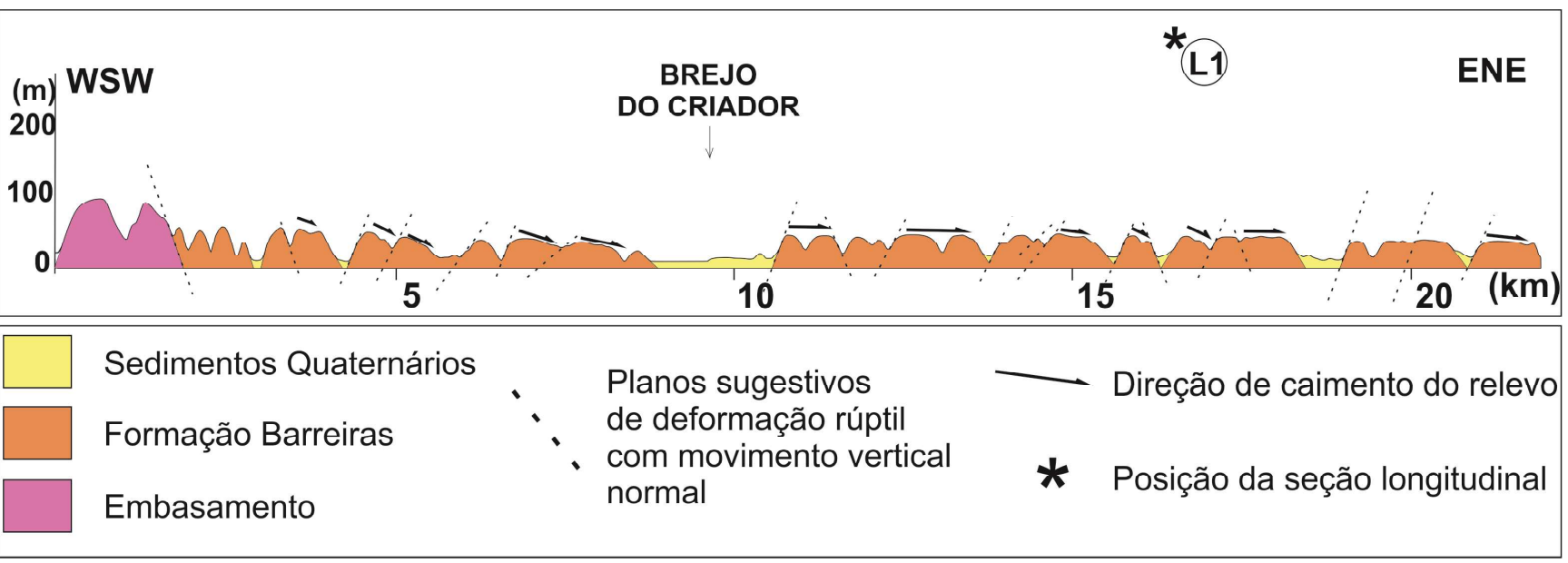

Figura 12 - Seção topográfica transversal (T1), com exagero vertical de aproximadamente 10 vezes. Ver localização na Figura 8. 
O refinamento do mapeamento através da fusão realçou os padrões da rede de drenagem sobre os depósitos da Formação Barreiras, permitindo maior contraste e distinção entre setores dos tabuleiros mais ou menos dissecados. Foram identificados padrões de drenagem paralelo a subparalelo (Figura 13). A geometria retilínea contínua de algumas drenagens encaixadas em direções preferenciais NW-SE, N-S e menos comumente NE-SW é interpretada como um possível indicador de controle estrutural/neotectônico na área de estudo.

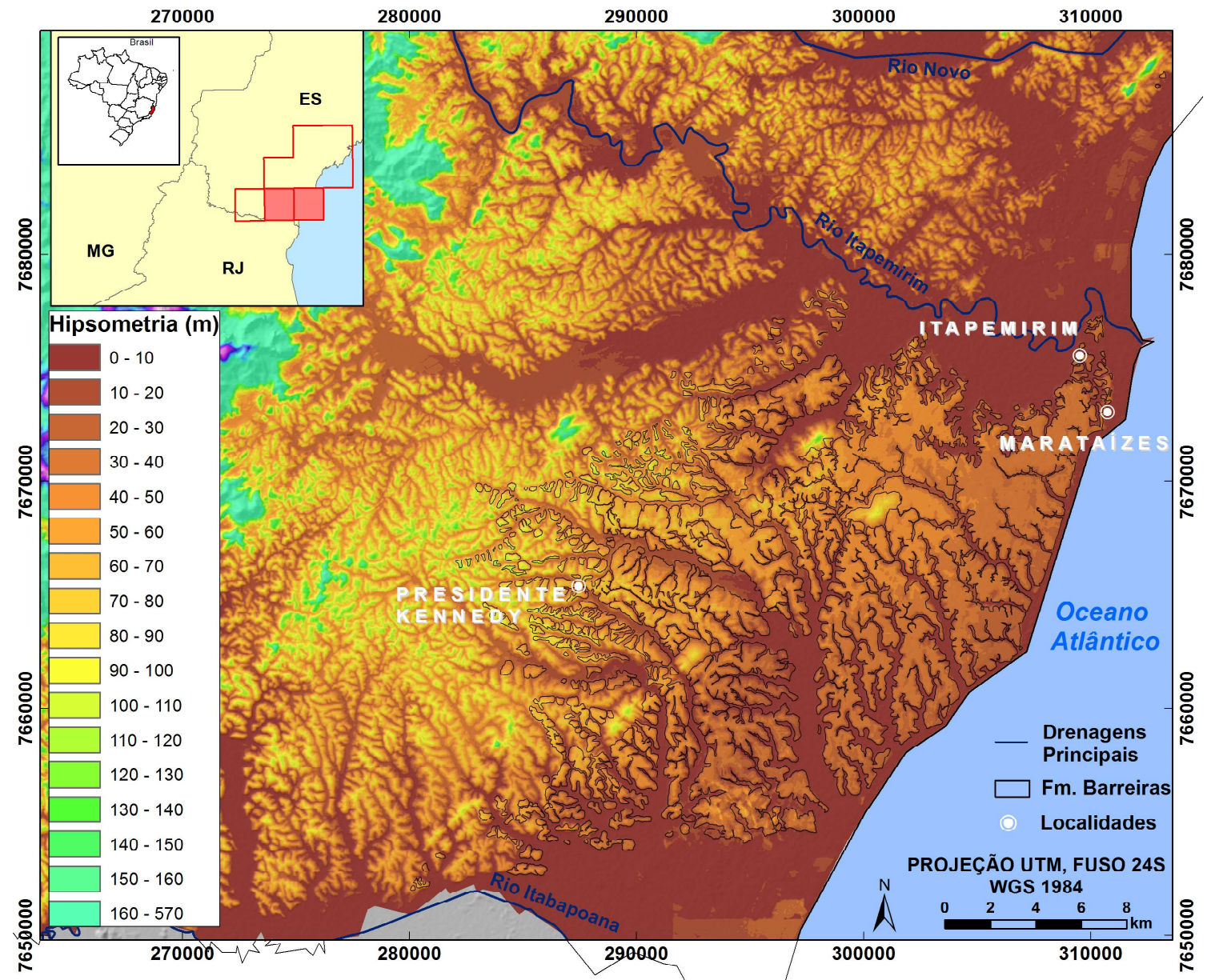

Figura 13-Mapa hipsométrico de parte da área de estudo, destacando a região entre os municipios de Presidente Kennedy (ES) e Itapemirim (ES), elaborado a partir do MDE do IEMA. Nota-se o padrão paralelo a subparalelo das drenagens sobre os tabuleiros da Formação Barreiras, encaixadas segundo direções preferenciais (predominantemente $N W$-SE e N-S), atribuindo ao conjunto de drenagens uma geometria poligonal. Também podem ser observadas "ilhas" de embasamento cristalino em meio aos tabuleiros, alinhadas na direção NE-SW.

\subsection{Análise de lineamentos}

Do total de 2.250 lineamentos com extensão mínima de 1.000 metros extraídos ao longo da área de estudo, $2.010(89,3 \%)$ foram traçados nos terrenos do embasamento e $240(10,7 \%)$ sobre os depósitos da Formação Barreiras (Figura 14).

Constata-se, para a área total, a predominância de lineamentos de orientação NE-SW (21,1\%), NW-SE $(20,4 \%)$ e WNW-ESE $(18,8 \%)$, perfazendo, em conjunto, aproximadamente $60 \%$ do total de lineamentos. Os demais intervalos apresentam menor frequência:
NNW-SSE (15,8\%); NNE-SSW (13,8\%); ENE-WSW (9,5\%). Quando analisados pelos domínios geológicos, essa distribuição se mantém praticamente inalterada no domínio do Embasamento Cristalino. Já no domínio da Formação Barreiras predominam os lineamentos NW-SE $(25,4 \%)$, NNW-SSE $(19,5 \%)$, WNW-ESE $(18,3 \%)$ e, somente depois, NE-SW (15,8\%), NNE-SSW (13,3\%), ENE-WSW (7,5\%). O padrão observado de distribuição de lineamentos é similar, de modo geral, ao descrito nos trabalhos realizados ao longo da região costeira do Espírito Santo por Ribeiro (2010), Bricalli (2011) e Bricalli \& Mello (2013). 


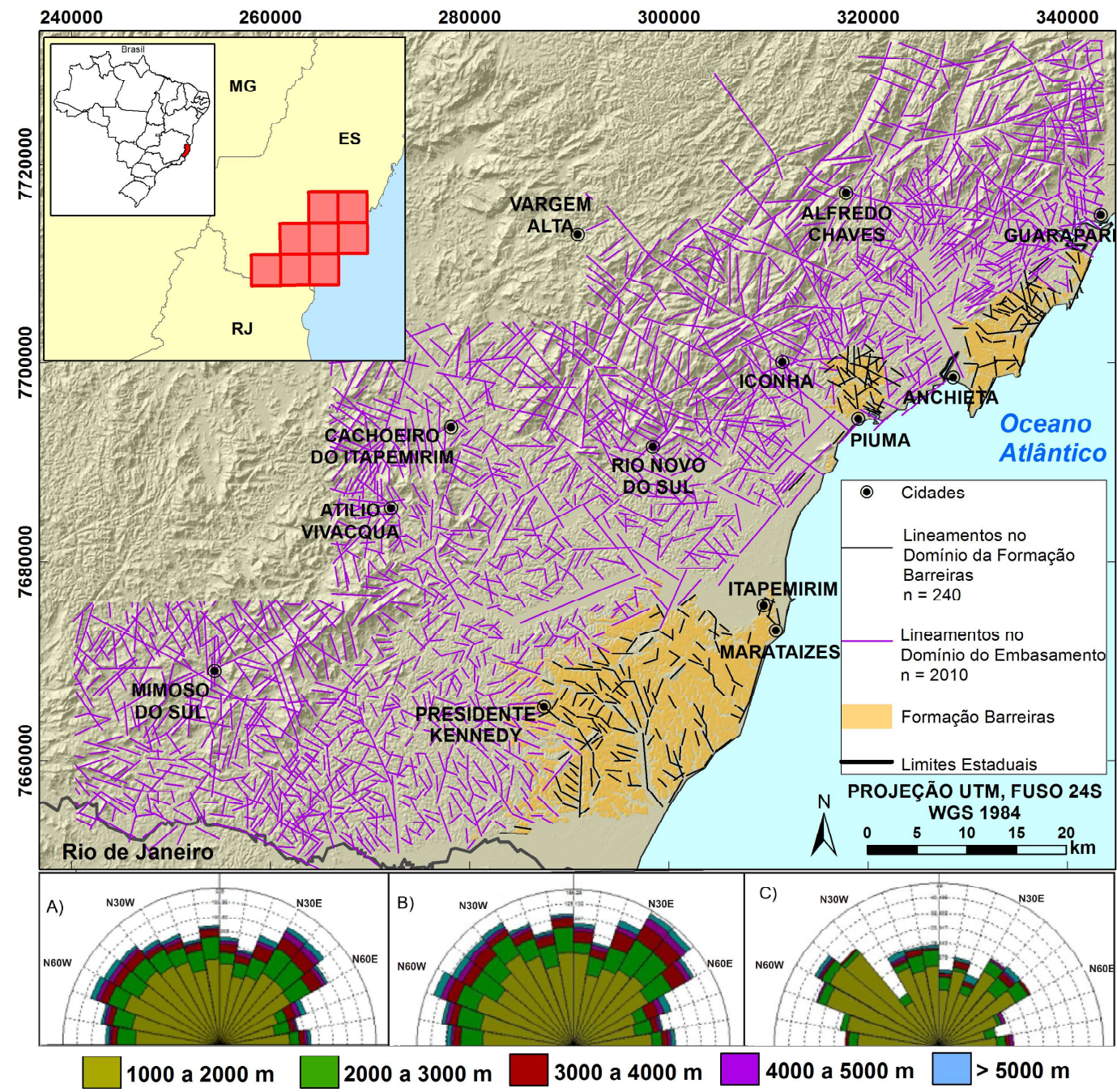

Figura 14-Mapa de lineamentos com extensão mínima de 1.000 metros traçados na área de estudo (total de 2.250 lineamentos), divididos pelos domínios do Embasamento e da Formação Barreiras, sobre o hillshade (azimute $315^{\circ}$ e altitude $45^{\circ}$ ) elaborado a partir do MDE do IEMA. São apresentadas também as rosetas de frequência e comprimento dos lineamentos para a área total (A) e para os domínios do Embasamento (B) e da Formação Barreiras (C).

Os lineamentos NE-SW nos terrenos da Formação Barreiras encontram-se adjacentes aos altos topográficos onde afloram rochas do embasamento em meio aos terrenos sedimentares. Alguns feixes de lineamentos NW-SE e NNW-SSE estendem-se claramente do domínio do embasamento para o domínio dos tabuleiros da Formação Barreiras, como, por exemplo, na região de Piúma e entre Anchieta e Guarapari, podendo ser relacionados à compartimentação da distribuição da Formação Barreiras.

Quanto ao comprimento dos lineamentos, há um predomínio de feições entre 1.000 e 2.000 metros, particularmente no domínio da Formação Barreiras (Figura 14). No domínio do Embasamento Cristalino os maiores comprimentos estão associados às direções NE-SW e
NW-SE. No domínio da Formação Barreiras, os maiores comprimentos estão concentrados nas direções NW-SE, NNW-SSE e NE-SW.

A análise dos lineamentos estruturais sugere controles tectônicos na área de estudo relacionados a duas orientações principais: NE-SW e NW-SE, também associadas à compartimentação dos tabuleiros da Formação Barreiras, conforme identificado nas seções topográficas/geológicas anteriormente apresentadas. $\mathrm{O}$ trend de lineamentos NE-SW, bem marcado no domínio do embasamento, sugere o controle pela reativação de estruturas relacionadas à Faixa Ribeira. $\mathrm{O}$ trend de lineamentos NW-SE se mostra aparentemente mais efetivo na deformação dos tabuleiros da Formação Barreiras. 


\subsection{Análise de paleotensões}

Dados estruturais obtidos por Ribeiro (2010) indicam três campos de paleotensões distintos afetando os terrenos do sul do Espírito Santo (Figura 15), correlacionados pela autora aos eventos de deformação neotectônicos propostos por Riccomini et al. (2004) para o Rift Continental do Sudeste do Brasil: i) falhas normais NE-SW afetando os depósitos da Formação Barreiras, identificadas nos pontos ITA-3 e RNS-2, relacionadas a uma distensão NW-SE, associada a evento distensivo holocênico; ii) falhas normais NW-SE e falhas sinistrais NNW-SSE e NNE-SSW afetando os depósitos da Formação Barreiras, identificadas nos pontos ITA-3 e RNS-2, relacionadas a uma distensão NE-SW, associada a evento de transcorrência dextral E-W, de idade Pleistoceno-Holoceno; iii) falhas dextral e sinistral NE-SW, afetando apenas rochas do embasamento saprolitizadas, identificadas no ponto ITA-3, relacionadas a uma distensão NW-SE e compressão
NE-SW, associada a evento de transcorrência sinistral E-W, neogênico.

No presente estudo, padrões de deformação semelhantes foram reconhecidos em três afloramentos (Figura 15), sendo associados a dois dos três campos de paleotensões propostos por Ribeiro (2010): i) falhas normais NE-SW afetando sedimentos da Formação Barreiras e coberturas mais recentes foram observadas nos pontos 57 (Figura 16) e 331, relacionadas ao evento holocênico de distensão NW-SE; ii) falhas normais NW-SE afetando sedimentos da Formação Barreiras, identificadas nos pontos 114 (Figura 17) e 331, e falhas transcorrentes sinistrais NNW-SSE a NNE-SSW e dextrais ENE-WSW, identificadas no ponto 331 afetando sedimentos da Formação Barreiras e rochas do embasamento saprolitizadas, são associadas a um campo de paleotensões distensivo NE-SW, compatível com o evento de transcorrência dextral E-W, de idade Pleistoceno-Holoceno.

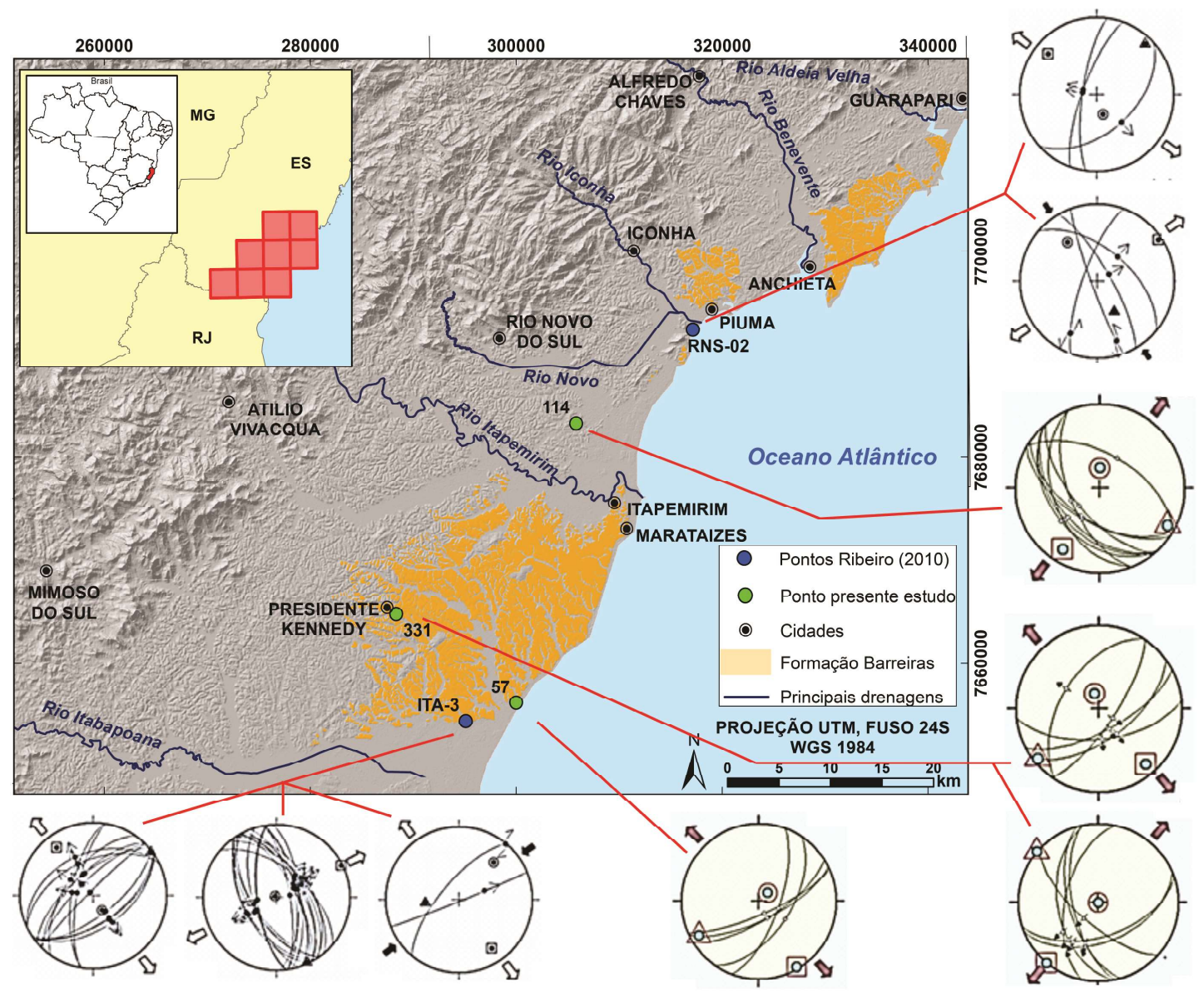

Figura 15 - Diagramas de paleotensões obtidos para conjuntos de dados estruturais descritos por Ribeiro (2010) - pontos ITA-3 e RNS-2, e no presente estudo - pontos 57, 114 e 331. Os pontos estão representados sobre o hillshade de azimute $315^{\circ}$ e altitude $45^{\circ}$, elaborado a partir do MDE do IEMA. 
West D. C. \& Mello C. L.

Os resultados obtidos na análise de paleotensões reforçam a existência de feições tectônicas com direções principais NE-SW e NW-SE afetando os tabuleiros da Formação Bar-

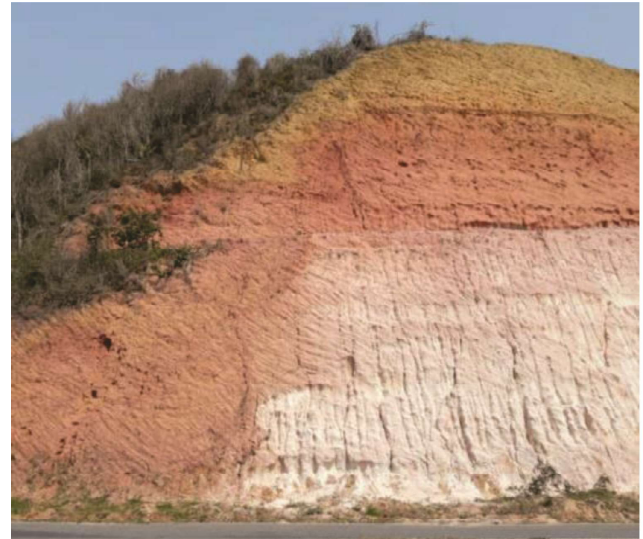

reiras, mesmo padrão sugerido pela análise de lineamentos e também verificado como controle da compartimentação das ocorrências da Formação Barreiras na área investigada.

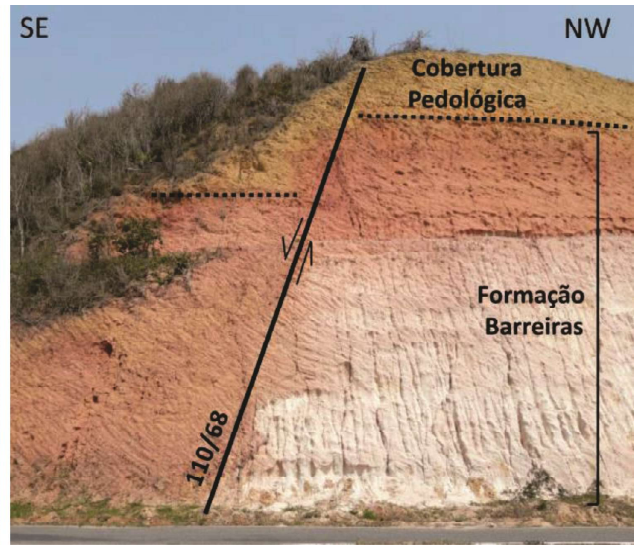

Figura 16 - Afloramento descrito no ponto 57, com destaque para falha normal de direção NE-SW, relacionada a evento holocênico de distensão NW-SE, afetando a Formação Barreiras e sua cobertura pedológica.
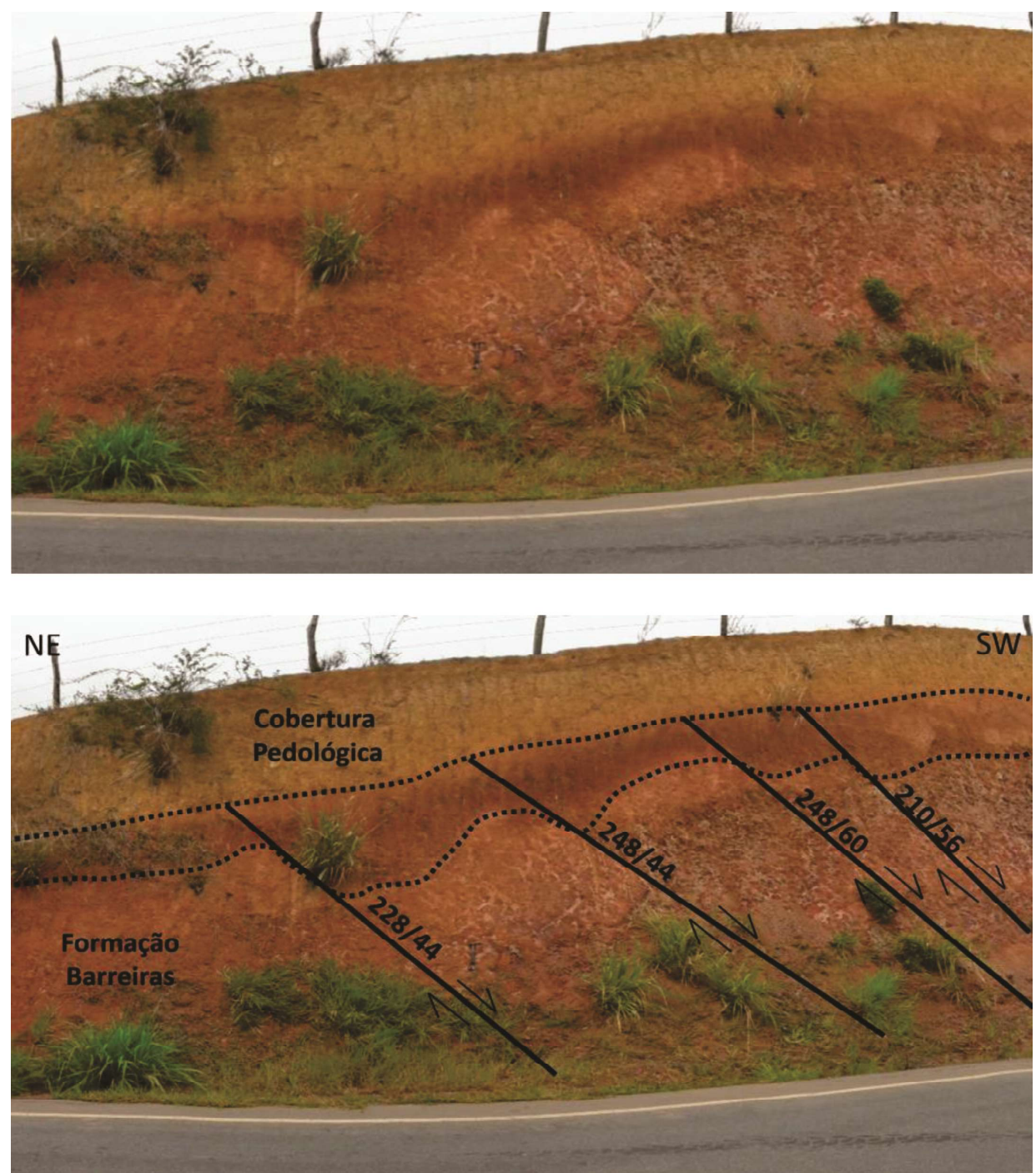

Figura 17-Afloramento descrito no ponto 114, com destaque para falhas normais de direção NW-SE, relacionadas a evento de transcorrência dextral E-W, de idade Pleistoceno-Holoceno, afetando a Formação Barreiras. 


\section{Conclusões}

Trabalhos anteriores voltados para o mapeamento da Formação Barreiras na região Sudeste do Brasil ressaltaram as dificuldades para a definição dos limites entre a unidade e os domínios colinosos do embasamento. O uso de um MDE de alta resolução mostrou-se ser uma ferramenta eficiente para essa delimitação, embora tenha sido indispensável uma checagem extensiva em trabalhos de campo. A fusão do MDE com suas ortofotos permitiu uma maior precisão no traçado dos limites entre os tabuleiros e colinas, assim como da drenagem instalada sobre os tabuleiros.

A distribuição da Formação Barreiras apresenta-se compartimentada segundo as direções principais NE-SW e NW-SE, de tal forma que feições NE-SW estão associadas aos contatos mais evidentes com o embasamento e limitam áreas com diferentes espessuras dos depósitos sedimentares, por vezes controlando setores com aspecto de "embaciamentos"; já as feições NW-SE individualizam as áreas de ocorrência da Formação Barreiras e controlam as principais drenagens que entalham os tabuleiros.

A concentração, no entorno do principal setor de distribuição da Formação Barreiras na região investigada, situado entre os rios Itabapoana e Itapemirim, de muitas ocorrências restritas a topos de colinas sugere que a área ocupada pela unidade foi mais extensa, sendo a dissecação posterior controlada por orientações NE-SW e NW-SE. Tais orientações, principalmente as de direção NW-SE, também condicionam a estruturação dos tabuleiros em blocos elevados, rebaixados e inclinados. Esse conjunto de aspectos morfológicos é atribuído à atuação de estruturas neotectônicas, corroborando interpretações apresentadas em estudos anteriores nessa região (Ribeiro, 2010).

A respeito dos mecanismos neotectônicos atuantes na compartimentação dos tabuleiros da Formação Barreiras na região sul do Espírito Santo, os dados estruturais obtidos ratificam os resultados apresentados por Ribeiro (2010) e Bricalli (2011), sendo reconhecidos dois eventos deformacionais: evento de transcorrência dextral E-W, cujo registro é mais expressivo e ao qual estariam associadas as feições NW-SE que limitam as áreas de ocorrência da Formação Barreiras, segmentam os tabuleiros em blocos e controlam as drenagens; e evento de distensão NW-SE, ao qual são atribuídas as feições NE-SW que delimitam áreas de contato com o embasamento, como provável reativação de estruturas da Faixa Ribeira, e também condicionam blocos dos tabuleiros. Considerando os eventos neotectônicos propostos por Riccomini et al. (2004) para o Rift Continental do Sudeste do Brasil, os eventos identificados são atribuídos, respectivamente, a idades Pleistoceno-Holoceno e Holoceno.

\section{Agradecimentos}

À CPRM (Serviço Geológico do Brasil/Companhia de Pesquisa de Recursos Minerais), pela disponibilização da base cartográfica para a execução do trabalho. Ao IGEO/UFRJ (Instituto de Geociências, Universidade Federal do Rio de Janeiro) e ao Programa de Pós-Graduação em Geologia/IGEO/UFRJ, pela infraestrutura necessária e auxílio financeiro para a realização do estudo. À Coordenação de Aperfeiçoamento de Pessoal de Nível Superior (CAPES) e à Fundação Carlos Chagas Filho de Amparo à Pesquisa do Estado do Rio de Janeiro (FAPERJ), pelo auxílio financeiro para o desenvolvimento da pesquisa, sob a forma de bolsa de Mestrado.

\section{Referências Bibliográficas}

ALVES, J. S. E. Faciologia do Grupo Barreiras no Sul do Estado do Espírito Santo. Trabalho de Conclusão de Curso (Bacharelado em Geologia). Centro de Ciências Exatas, Naturais e da Saúde, Departamento de Geologia, Universidade Federal do Espírito Santo, Alegre. 2016. 69 p.

ANGELIER, J. (1994). Fault slip analysis and paleostress reconstruction. In: HANCOCK, P.L. (org.). Continental Deformation. Pergamon Press, Oxford: 1st ed., 1994. p. 53-100.

ARAI, M. A. grande elevação eustática do Mioceno e sua influência na origem do Grupo Barreiras. Geologia USP (Série Científica), n. 6, p. 1-6, 2006

BEZERRA F.H.R., ROSSETTI D.F., OLIVEIRA R.G., MEDEIROS W.E., BRITO NEVES B.B., BALSAMO F., NOGUEIRA F.C.C., DANTAS E.L., ANDRADES FILHO C., GOES A.M. Neotectonic reactivation of shear zones and implications for faulting style and geometry in the continental margin of NE Brazil. Tectonophysics, v. 614, p. 78-90, 2014.

BRÊDA, T. C. Análise multiescalar da Formação Barreiras na área emersa da bacia de Campos, entre Búzios e Campos dos Goytacazes (RJ). Dissertação (Mestrado em Geologia). Instituto de Geociências, Universidade Federal do Rio de Janeiro, Rio de Janeiro. 2012. 112 p. 
BREDA, T. C.; MELlO, C. L.; MORAES, A. Significado Tectônico de Padrões de Lineamentos na Porção Emersa das Bacias Marginais do Sudeste do Brasil e Áreas de Embasamento Adjacentes. Anuário do Instituto de Geociências (UFRJ), v. 41, p. 305-318, 2018.

BRICALLI, L. L. Padrões de lineamentos e fraturamento neotectônico no estado do Espírito Santo (Sudeste do Brasil). Tese (Doutorado em Geologia). Instituto de Geociências, Universidade Federal do Rio de Janeiro, Rio de Janeiro. 2011. $221 \mathrm{p}$.

BRICALLI, L. L.; MELLO, C. L. Padrões de lineamentos relacionados à litoestrutura e ao fraturamento neotectônico (Estado do Espírito Santo, Sudeste do Brasil). Revista Brasileira de Geomorfologia, v.14, n 3, p.301-311, 2013.

CHRISMANN, J. V. V. Mapeamento da Formação Barreiras na Região Norte Fluminense, entre os Rios Paraíba do Sul e Itabapoana. Trabalho de Conclusão de Curso (Bacharelado em Geologia). Instituto de Geociências, Universidade Federal do Rio de Janeiro, Rio de Janeiro. 2014. 49 p.

DELVAUX, D. \& SPERNER, B. (2003). Stress tensor inversion from fault kinematic indicators and focal mechanism data: the TENSOR program. In: DELVAUX, D. \& SPERNER, B (org.). New Insights into Structural Interpretation and Modelling. D. Nieuwland Ed., Geological Society, London, Special Publications: v. 212, p. 75-100.

FURRIER, M; ARAÚJO, M. E.; MENESES, L.F. Geomorfologia e Tectônica da Formação Barreiras no Estado da Paraíba. Geologia USP (Série Científica), v. 6, n. 2, p. 61-70, 2006.

LIMA, M. G. A história do intemperismo na província Borborema Oriental, Nordeste do Brasil: implicações paleoclimáticas e tectônicas. Tese (Doutorado em Geodinâmica). Universidade Federal do Rio Grande do Norte, Rio Grande do Norte. 2008. 251 p.

LIU, C. C. A geologia estrutural do estado do Rio de Janeiro vista através de imagens MSS de Landsat. In: Simpósio de Geologia Regional RJ-ES, 1987, Rio de Janeiro. Anais... Rio de Janeiro: SBG. 1987. p. 164-188.

MORAIS, R. M. O. Sistemas fluviais terciários na área emersa da bacia do Espírito Santo (Formações Barreiras e Rio Doce). Tese (Doutorado em Geologia). Instituto de Geociências, Universidade Federal do Rio de Janeiro, Rio de Janeiro. 2007. 144 p.

NOGUEIRA, F. C. C.; BEZERRA, F. H. R.; CASTRO, D. L. Deformação rúptil em depósitos da Formação Barreiras na porção leste da Bacia Potiguar. Geologia USP(Série Cientifica), v. 6, n. 2, p. 51-59, 2006.

RIBEIRO, C. S. Influência da tectônica pós-deposicional na distribuição da Formação Barreiras entre o rio Paraíba do Sul (RJ) e rio Doce (ES). Dissertação (Mestrado em Geologia). Instituto de Geociências, Universidade Federal do Rio de Janeiro, Rio de Janeiro. 2010. 163 p.

RODRIGUES, L. O. M. Análise de lineamentos e de dados estruturais neotectônicos na região norte-fluminense, entre os rios Paraíba do Sul e Itabapoana. Trabalho de Conclusão de Curso (Bacharelado em Geologia). Instituto de Geociências, Universidade Federal do Rio de Janeiro, Rio de Janeiro. 2015. $48 \mathrm{p}$.

SAADI, A. (1999). Neotectônica dos tabuleiros do sul da Bahia. In: MME/SMM/CPRM/SR Salvador. (Org.). Programa Informações para Gestão Territorial: Projeto Porto Seguro - Santa Cruz Cabrália. Salvador-BA, Companhia de Pesquisa de Recursos Minerais-CPRM: v. 3, p. 40-55.

SHINZATO, E.; RENK, J. F. C.; DANTAS, M. E.; TEIXEIRA, W. G.; VARGAS, L. Geotecnologia 3D na compartimentação geomorfológica das bacias hidrográficas dos rios Macacu e Caceribu - Recôncava da baixada da Guanabara/RJ. In: IX SINAGEO, 9, 2012, Rio de Janeiro. Anais... Rio de Janeiro: SINAGEO. 2012. p. 407.

SILVA, S. F. \& MACHADO, M. F. (org.). Geodiversidade do estado do Espírito Santo. Companhia de Pesquisa de Recursos Minerais (CPRM), Programa Geologia do Brasil, Levantamento da Geodiversidade, Belo Horizonte. 2014. 120 p.

SUGUIO, K.; NOGUEIRA, A. C. R. Revisão critica dos conhecimentos geológicos sobre a formação (ou Grupo?) Barreiras do neógeno e o seu possível significado como testemunho de alguns eventos geológicos mundiais. Geociências, v. 18 , n. 2, p. 461-479, 1999.

VIEIRA, V. S. \& MENEZES, R. G. (org.). Geologia e Recursos Minerais do Estado do Espírito Santo: texto explicativo do mapa geológico e de recursos minerais, escala 1:400.000. Companhia de Pesquisa de Recursos Minerais (CPRM), Programa Geologia do Brasil Belo Horizonte. 2015. 289 p.

WEST, D. C. Mapeamento geológico (Escala 1:25.000) e modelo tectonossedimentar para a Formação Barreiras no sul do estado do Espírito Santo. Trabalho de Conclusão de Curso (Bacharelado em Geologia). Instituto de Geociências, Universidade Federal do Rio de Janeiro, Rio de Janeiro. 2017. $72 \mathrm{p}$. 